\title{
The image of a point charge in an infinite conducting cylinder
}

matt majic ${ }^{1}$

${ }^{1}$ Victoria University of Wellington

May 5, 2020

\begin{abstract}
The electrostatics problem of a point charge next to a conducting plane is best solved by placing an image charge placed on the opposite side. For a charge between two parallel planes this can be solved with image charges outside the planes at evenly spaced intervals moving out to infinity. What is the corresponding image of a point charge is when placed on the axis of a cylinder?. The potential of a point charge in a cylinder is well known and may expressed in many forms involving integrals or series of Bessel functions, but none of which elude to an image. In fact the image consists of infinitely many rings on a disk with some complicated surface charge distribution. This manuscript attempts to describe the image as accurately as possible, and in doing so finds simple accurate approximations for the potential.
\end{abstract}

\section{Hosted file}

ImageCylinder.pdf available at https://authorea.com/users/301075/articles/430854-the-imageof-a-point-charge-in-an-infinite-conducting-cylinder

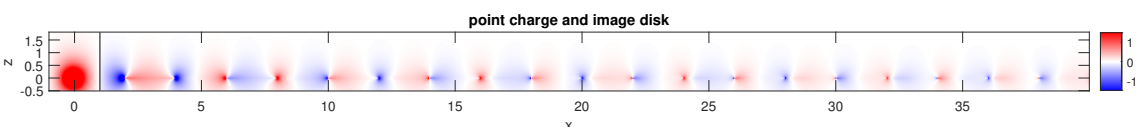




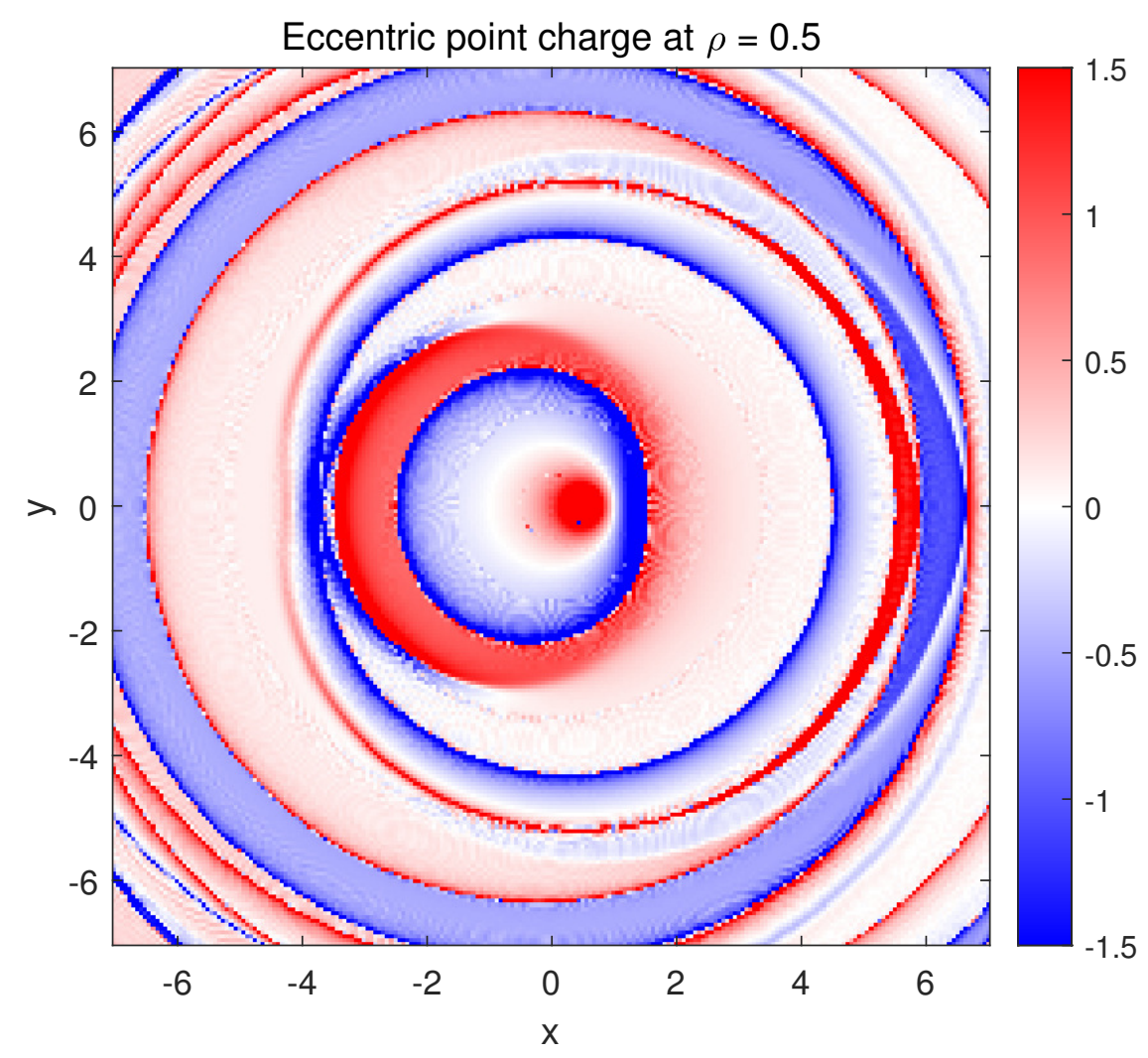




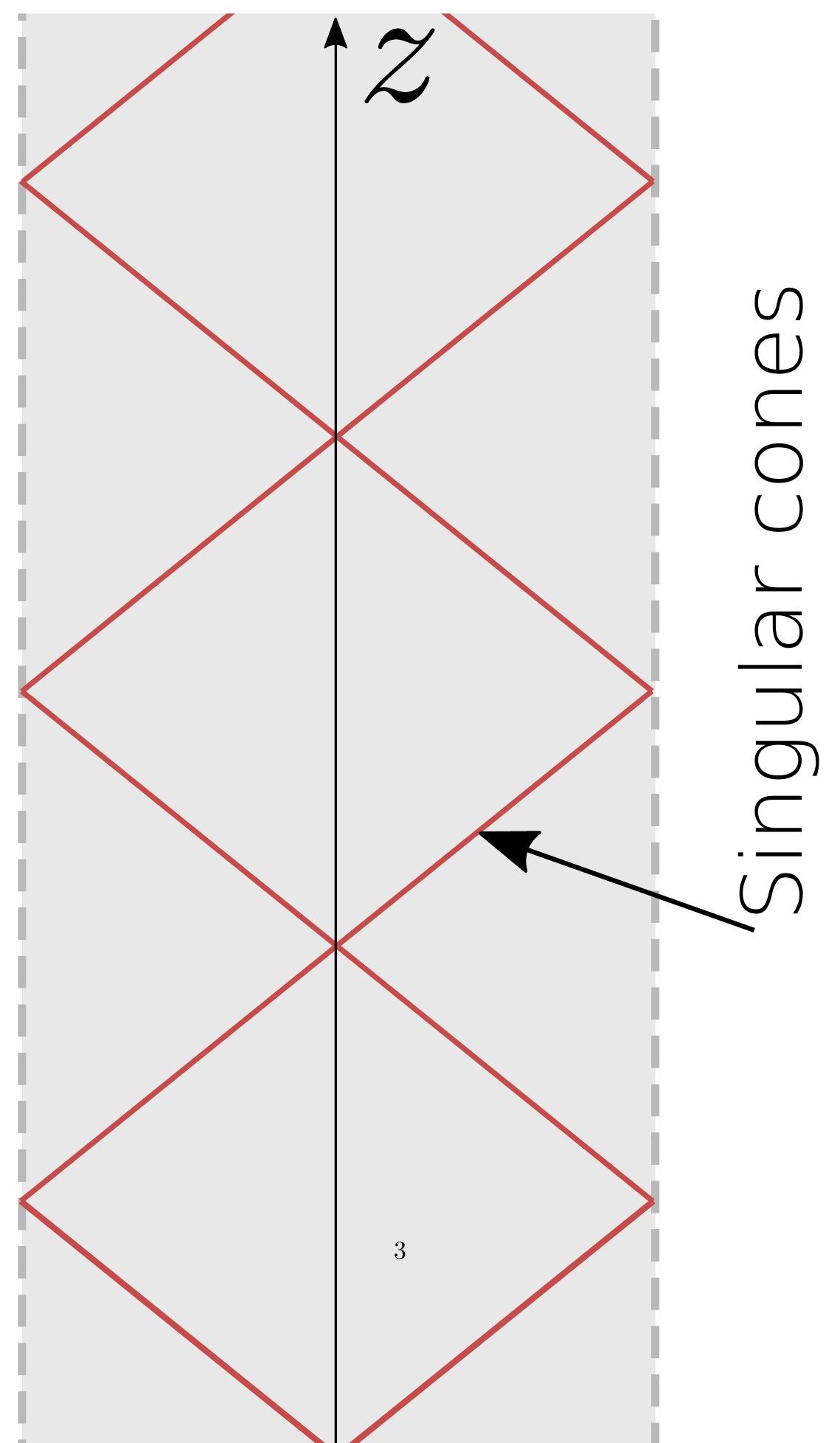




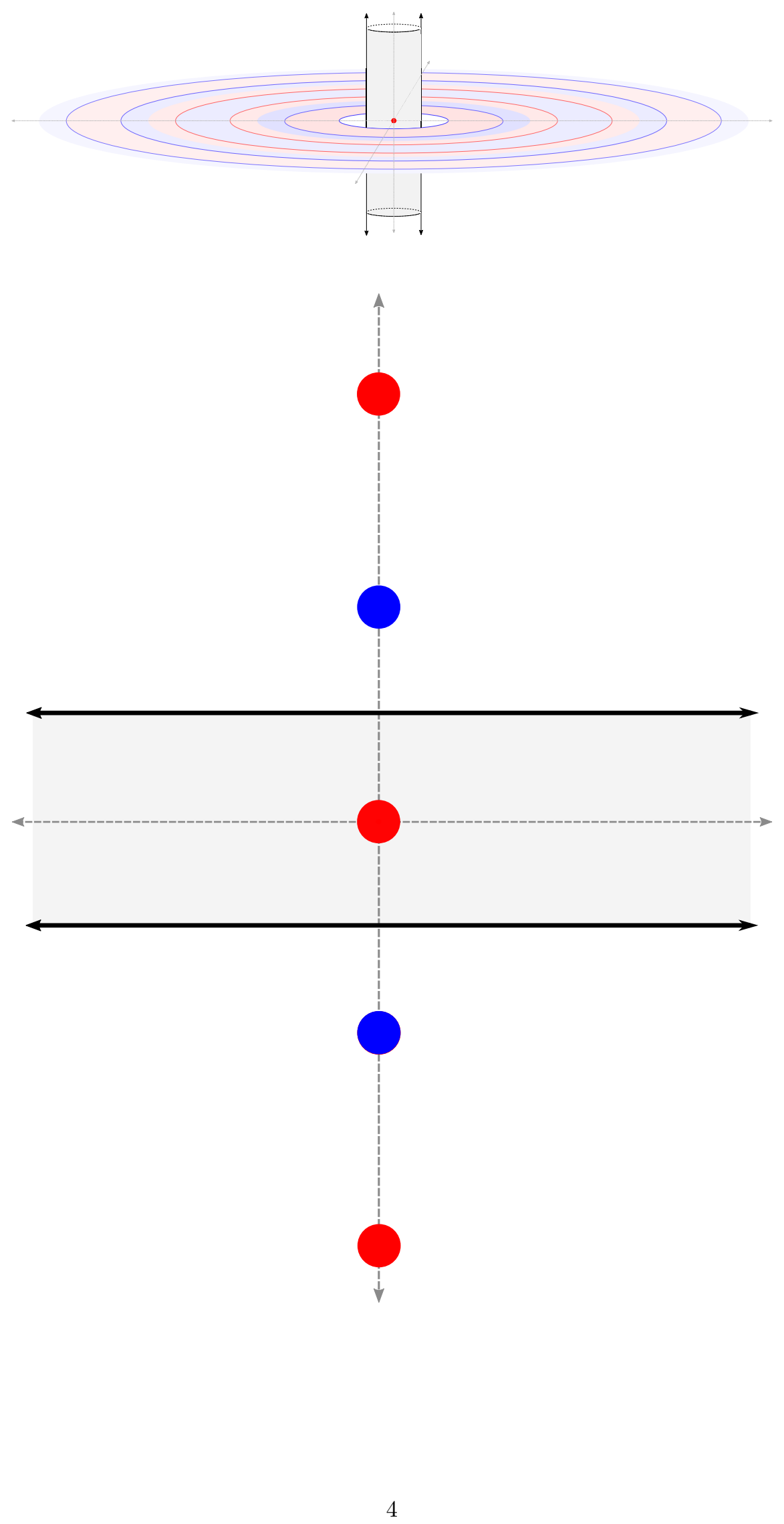



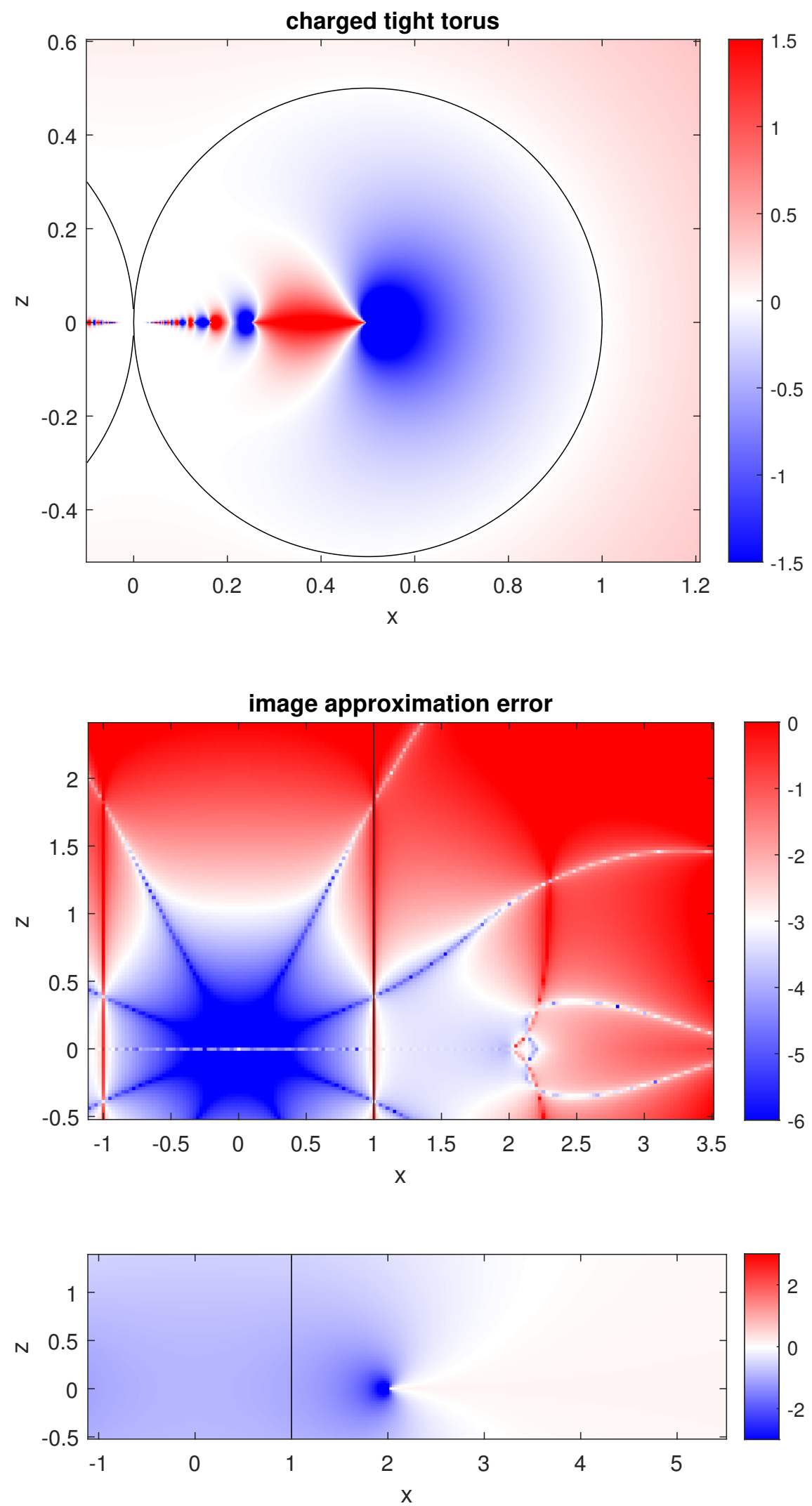

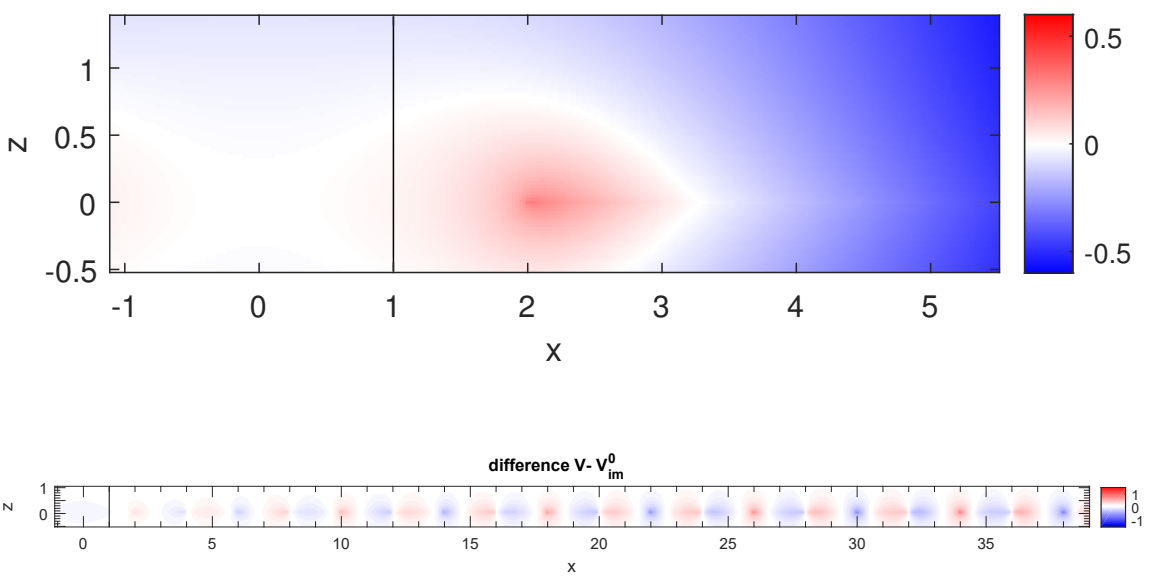

image approximation $v_{i m}^{0}$
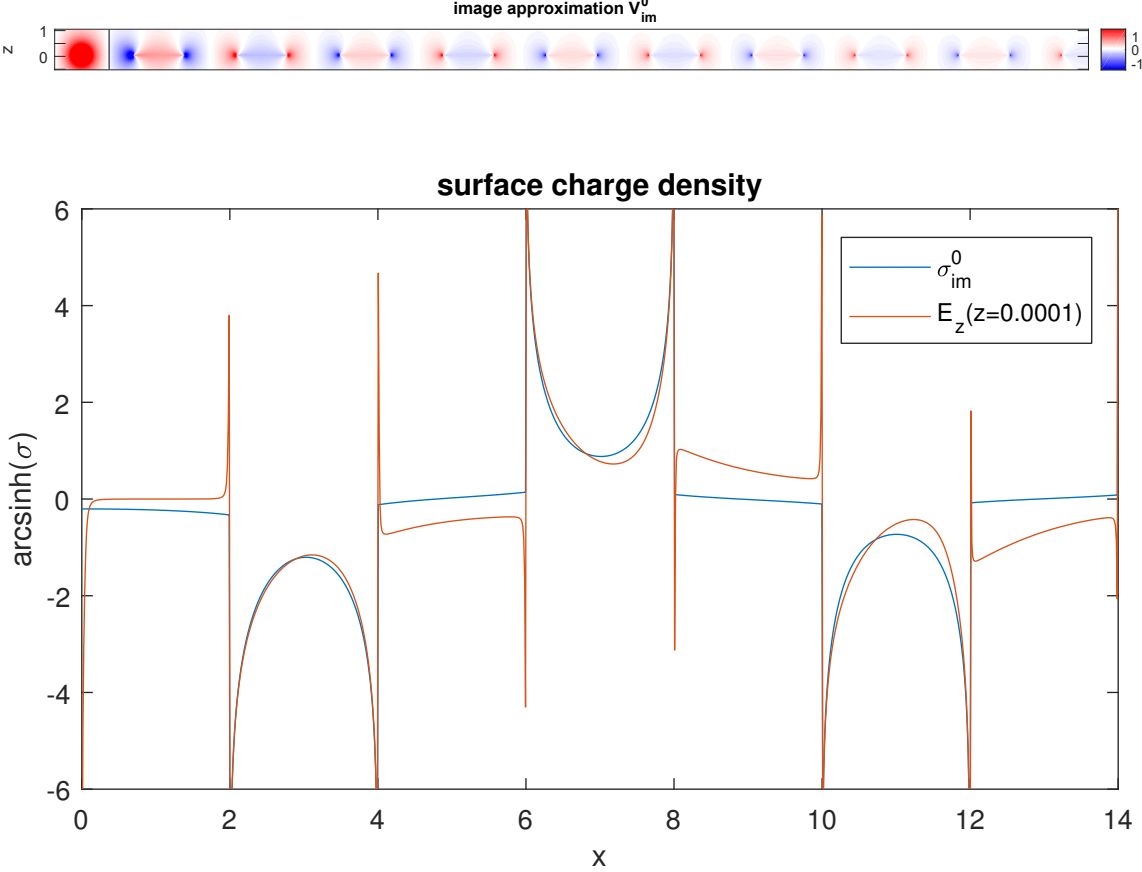